\title{
Enzymatic upgrade of old paperboard containers
}

\author{
H. Pala, M.A. Lemos, M. Mota, F.M. Gama* \\ Centro de Engenharia Biológica - IBQF, Universidade do Minho, Largo do Paço, 4719 Braga Codex, Portugal
}

Received 13 February 2001; received in revised form 30 April 2001; accepted 22 May 2001

\begin{abstract}
The use of enzymes in secondary fiber (old paperboard containers) upgrading was investigated. The following aspects were analyzed: (i) the effect of several enzymes and (non-hydrolytic) cellulose-binding domains on the pulp and paper properties; (ii) factors influencing enzymatic treatment of secondary fiber: enzyme dosage and reaction time; and (iii) enzyme action on fractions with different fiber-length. In general, all the tested enzymatic preparations were able to improve the pulp drainability. In most cases this improvement was obtained at the expense of paper strength. The use of cellulose-binding domains allowed for the simultaneous increase in drainability and strength properties. (C) 2001 Elsevier Science Inc. All rights reserved.
\end{abstract}

Keywords: Cellulase; Cellulose binding-domains; Pulp and paper; Drainage; Physical properties

\section{Introduction}

The incorporation of secondary fiber in paper production affects the final product quality and the papermaking process. Basically, these changes are caused by the inferior fiber quality (length, flexibility) and the higher drainage resistance of recycled pulps. The first affects inter-fiber bonding and consequently paper strength. The second makes sheet formation more difficult, decreases the papermachine runnability and increases energy consumption in the dryers [1-3].

Several upgrading techniques are known, namely alkali treatment, refining/beating processes, additive usage or nonwood plant fiber incorporation. However, their advantages to paper manufacture are sometimes limited as they do not assure the simultaneous increase in paper resistance and pulp drainage ability [3-5]. The use of enzymes is a promising alternative [1,6-10].

The action of cellulases and hemicellulases on the fiber components can result in improved inter-fiber bonding and decreased fiber-water interactions. Although the mechanisms are not completely understood, several theories are currently used to explain the effect of the enzymes on the paper technical properties $[1,8,11]$. An enzymatic treatment for a particular pulp is still very difficult to develop, because, for each pulp, every procedure (enzyme selection, concentration, etc) has to be optimized [8,11-13].

\footnotetext{
* Corresponding author. Tel.: +351-253-604400; fax: +351-253678986.
}

Further knowledge on the complex "fiber-enzyme" interactions and more data on the effect of enzymatic treatments on the pulp and paper properties are necessary in order to develop a rational design of enzymatic fiber upgrading [14-16].

\section{Materials and methods}

\subsection{Enzymatic preparations}

Several Commercial Enterprises or Research Institutes kindly supplied the enzymatic preparations used. Their relevant characteristics are presented in Table 1. The protein concentration was determined by the Bradford method [17]. The calibration curve was made using bovine serum albumin as standard.

The endoglucanase, cellulase and xylanase activities were measured using the CarboxyMethylCellulase (CMCase), Filter Paper (FPase) and xylan oat spelt assays, as described in Pommier et al. (1989). Released sugars were measured by the DiNitroSalicylic acid method (DNS), using glucose as standard [18].

\subsection{Cellulose-binding domains}

The Cellulose-Binding Domains (CBD) tested in this work were produced according to the protocol described in Lemos et al. (2000). The protein in the CBDs solutions was measured using the Bradford method [17]. 
Table 1

Enzyme characterisation and concentrations used in the pulps treatment; quantification of cellulose degradation

\begin{tabular}{|c|c|c|c|c|c|c|c|}
\hline \multirow[t]{2}{*}{ ENZYME } & \multirow[t]{2}{*}{ Supplier } & \multicolumn{2}{|l|}{ Protein } & \multirow{2}{*}{$\frac{\text { FPase }}{\text { FPU/g* }}$} & \multirow{2}{*}{$\frac{\text { CMCase }}{\mathrm{U} / \mathrm{g} *}$} & \multirow{2}{*}{$\frac{\text { Xylanase }}{U / g^{*}}$} & \multirow{2}{*}{$\begin{array}{l}\% \\
\text { solubilisation }\end{array}$} \\
\hline & & $\mathrm{mg} / \mathrm{cm}^{3 * *}$ & $\mathrm{mg} / \mathrm{g} *$ & & & & \\
\hline Xylanase C482 & INETI & 1 & 2.00 & 0.40 & 0.08 & 114 & 1.6 \\
\hline$P$. ocitanis $L$ & CBSfax & 11 & 1.44 & 2.23 & 1.13 & 49 & 2.2 \\
\hline P. ocitanis $S$ & CBSfax & $80(\mathrm{mg} / \mathrm{g})$ & 2.39 & 4.07 & 0.22 & 95 & 4.5 \\
\hline Termamyl & Novo & 52 & 1.40 & 0.00 & 0.01 & 27 & 0.1 \\
\hline Viscozyme & Novo & 43 & 1.46 & 0.54 & 0.31 & 24 & 0.3 \\
\hline Pergalase N2O & Genencor & 28 & 8.68 & 1.55 & 0.96 & 146 & 0.8 \\
\hline Ecostone L & Alko Ltd. & 58 & 1.65 & 2.17 & 0.11 & 100 & 2.0 \\
\hline Celluclast $1.5 \mathrm{~L}$ & Novo & 94 & 0.36 & 0.22 & 0.10 & 3 & 0.7 \\
\hline Primalco $H$ & Primalco & 46 & 0.35 & 0.07 & 0.02 & 12 & 0.6 \\
\hline Primalco $G$ & Primalco & 23 & 0.35 & 0.06 & 0.04 & 34 & 1.7 \\
\hline
\end{tabular}

* Enzyme dosage used in the pulp treatments expressed per gram of oven-dry pulp.

** Protein concentration in the cocktails as provided by the suppliers; CBSfax: Centre de Biotechnologie de Sfax, Tunisie; INETI: Instituto Nacional de Engenharia e Tecnologia Industrial, Lisboa, Portugal.

\subsection{Paper source}

The paper pulp used in this study was kindly supplied by the paper company Portucel Viana and consisted on Old Paperboard Containers, representing a mixture of $60 \% \mathrm{Kraft}$ paper, $20 \%$ fluting and $20 \%$ test liner.

\subsection{Fiber fractionation}

The secondary pulp obtained through the disintegration of the old paperboard containers was fractionated using a Bauer-McNett fiber-length classifier, and the $>30$ mesh and the 200-50 mesh fiber-length fractions were collected. The procedure followed the proposed standard routine (Tappi $233 \mathrm{~cm}-82$ ).

\subsection{Enzymatic/CBD pulping}

$30 \mathrm{~g}$ oven-dried (o.d.) of old paperboard containers pulp or $12 \mathrm{~g}$ (o.d.) of fractionated old paperboard containers pulp were processed. The pulp suspensions were prepared by disintegrating the samples in sodium citrate buffer $0.05 \mathrm{M}$, $\mathrm{pH}$ 5.0, for $10 \mathrm{~min}$. This mechanical treatment allows fiber separation, without appreciably changing their structural properties. After the disintegration step, the enzyme was added to the mixer according to the values mentioned in Table 1 . The enzymatic preparations were diluted $(10 \%$ of the total reaction volume) before to being added to the pulp, so that better dispersion was achieved. The reaction with the pulp occurred for $30 \mathrm{~min}$ at $3 \%$ consistency and $50^{\circ} \mathrm{C}$, with continuous slow mixing. The 30 -min period was selected according to previous reports on pulp treatments $[1,4,11,14]$ and also because preliminary assays revealed extended cellulose solubilisation after longer periods of time. To finish up the trial, the enzyme was deactivated either by increasing $\mathrm{pH}$ to alkaline values [8-10] and boiling the pulp for 5 min or by boiling the pulp. In order to estimate the enzymatic action conveniently, control assays (with denatured enzyme) were made in parallel.
Two of the enzymes in Table 1 were tested using different dosage and/or reaction time: Celluclast $1.5 \mathrm{~L}(0-1.7$ FPU/g (o.d.) pulp; 10/30/120 min) and Primalco G (0-0.06 FPU/g (o.d.) pulp; $30 \mathrm{~min})$. The experimental protocol used was similar to the one described above.

The pulp treatment (30 g (o.d.)) with CBD $(0.4-2.8 \mathrm{mg} / \mathrm{g}$ (o.d.) pulp) occurred under the same experimental conditions, but the final deactivation operation was not included. The control assays were made in the absence of CBD.

Each experimental condition (enzymatic assay or control) was tested 2-4 times and a good reproducibility was found between the results. The coefficients of variation (drainage, tensile, burst and tear) did never exceed $2 \%$.

\subsection{Samples recovery and quantification of cellulose degradation}

Samples were recovered by dewatering in a vacuum filter. The filtrate was kept so that the cellulose solubilisation during treatment could be quantified by measuring the present amount of reducing sugars, using the DNS method [18].

\subsection{Physical and mechanical properties determination}

Handsheet preparation and determinations of the pulp and paper properties were achieved according to the usual standard procedures: drainage rate (ISO 5267/1), burst (ISO 2758), tensile strength (ISO 1924/2), tear (ISO 1974), sheet density (ISO 534) and permeability to air flow (ISO 5636/3).

\section{Results and discussion}

\subsection{Fiber upgrading using enzymes and cellulose-binding domains}

The goal of this part of the study was to identify the most effective enzymes to improve the pulp and paper properties 


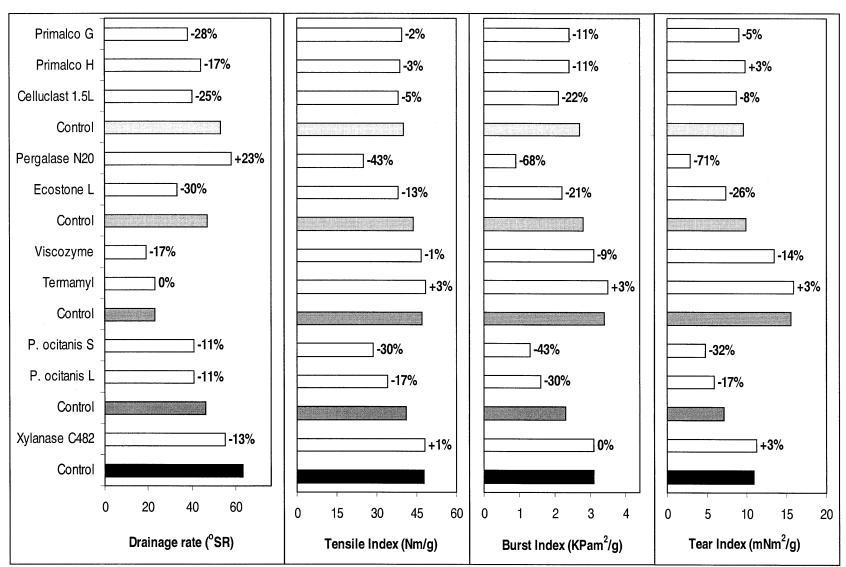

Fig. 1. Effect of the enzymatic treatment on the properties of pulp and paper (old paperboard containers). Drainage, tensile, burst and tear variation in enzymatic assays was expressed as percentage of the control. Different controls for the several enzymes correspond to different batches of old paperboard containers pulp.

and to understand whether the effectiveness depends on a specific type of activity. Cellulose-Binding Domains (CBD) were also used, in order to check whether the adsorption of the peptides on the paper fibers alone introduced significant changes in the fiber properties, or not.

The effect of the tested enzymes on the pulp and paper physical properties was analyzed by measuring pulp drainability and paper tensile, burst and tear resistance (Fig. 1). Most of the tested enzymes were responsible for a drainage improvement. However, this benefit was often obtained at the expense of paper strength. Such an unwanted effect would considerably reduce the interest of using these enzymes as drainage aids. The changes that occurred on the pulp and paper physical properties greatly depend on the enzyme used. Xylanase C482 allowed a ${ }^{\circ} \mathrm{SR}$ (SchopperRiegler degree, drainage measurement unit) decrease and caused no damage on the paper strength. P.ocitanis $L$ and $S$ were responsible for a similar ${ }^{\circ} \mathrm{SR}$ decrease (11\%) but, in contrast, led to a very important reduction in all the tested resistances. Although decreasing the paper strength properties, Primalco $G$ and $H$, Celluclast 1.5L, Ecostone $L$ and Viscozyme, revealed to be the most effective enzymes to improve drainage. Termamyl, a commercial amylase, did not alter either drainage or paper resistance, while Pergalase $N 20$ produced the worst results in the pulp and paper properties.

Understanding the enzymes behavior toward the fibers is essential to minimize the related negative effects. In general, cellulase treatments are reported as detrimental to pulp strength $[1,8,9,11]$. Only rarely the cellulolytic treatment can introduce alterations in the fiber morphology, namely fiber flexibility and collapsibility, which result in both enhanced conformability and inter-fiber bonding and improved sheet consolidation and network packing [21]. Indeed, the enzymes with higher FPase activity (Ecostone, Pergalase and P.ocitanis $L / S$ ) produced important reduc- tions in the paper strength properties. The hemicellulase treatments are frequently described as not interfering with paper strength, unless cellulase activity is also present. Xylan removal from the fibers surface may reduce the total charge [20,21]. In fact, taking into account the improvements achieved in the pulp drainability, the xylanases $C 482$ and Primalco showed the lowest effect on the strength parameters. The combined action of the two activities may provide a better upgrade of the secondary pulp although dependent of the applied dosage and reaction time. Our results showed that there is not such a simple relation of opposition between the enzymatic activity distribution (Table 1) and the modifications of the pulp and paper physical properties (Fig. 1). Other properties of the enzymes are important (processitivity, adsorption, etc). The presence of non-identified secondary activities may have a significant synergistic effect on the overall performance over the pulp.

Similar results were published by other authors. Pommier et al. (1989) reported a ${ }^{\circ} \mathrm{SR}$ decrease of $23 \%$ and a consequent burst decrease of $11 \%$ (laboratory handsheets measurements). Jackson et al. (1993) found a drainage improvement of 18 to $31 \%$, with a decrease of $16 \%$ in burst and 7 to $12 \%$ in tear. Stork and Puls (1994) also obtained a significant improvement in the secondary fiber ${ }^{\circ} \mathrm{SR}$, but at the expense of resistance, measured as tear and breaking length. Mansfield et al. (1996) reported a 2-4\% drainage increase followed by a great decrease in resistance (11-29\% in tensile, $0-32 \%$ in burst and $25-75 \%$ in tear indexes).

Pommier et al. (1989) suggested that extensive fiber degradation could be responsible for a dramatic strength loss. This was probably the case of P.ocitanis $L / S$ and Ecostone L, where the measured solubilised sugars indicated a more significant enzymatic activity and the pulp and paper characteristics were affected (Table 1). However, dramatic changes on the paper properties also occurred when only slight degradation took place (e.g. Celluclast $1.5 \mathrm{~L}$ versus Pergalase N20). These modifications could be better explained by a specific mode of attack on critical points of microfibers, as proposed by Jaako Pere et al. (1995). In fact, this author reported a $50 \%$ pulp viscosity decrease and considerable decrease in resistance, when cellulose degradation was lower than $1 \%$. The hypothesis of surface properties modification following enzyme adsorption should also be considered.

The present study revealed that enzymatic treatment caused sheet densification (data not shown), increasing its values by $1 \%$ to $3 \%$. The likely explanation for the increased density is that the enzymes affected the fibers to the extent that they collapsed under pressure during handsheet formation. Yet, density variation could not be related to any specific enzymatic activity or enzyme dosage. The fiber flattening is currently related to increased bonded area between fibers and strength properties improvements of resultant sheets [21]. Exception made for Xylanase C482 and Termamyl, such results were not visible in this work.

A significant increase of the handsheets permeability to 


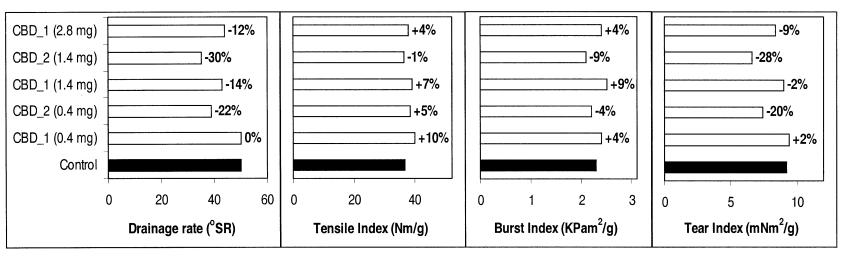

Fig. 2. Effect of the CBD application on the properties of pulp and paper (old paperboard containers).

airflow was also detected (data not shown), which seems to be related to a more significant enzymatic hydrolysis. P.ocitanis $L / S$ and Ecostone $L$ improved permeability by $150-$ 250\%. Primalco G, Celluclast $1.5 \mathrm{~L}$ and Primalco $\mathrm{H}$ induced a moderate increase $(82 \%, 80 \%$ and $37 \%$, respectively). Only Xylanase C482 and Pergalase N2O did not follow this trend. The first enzyme (1.6\% substrate hydrolysis), induced a $15 \%$ decrease in permeability, while the second enzyme ( $0.8 \%$ hydrolysis), was responsible for a $120 \%$ increase in the permeability parameter. Permeability can be related to the amount of filler in the pulp. If the resistance to air flow decreased, it is possible to establish that handsheet porosity increased after treatment. This could explain the paper strength lowering as a result of the amount of fines reduction, which could not be compensated through increased interfiber bonding. The overall strength decrease could also be related to a fiber intrinsic resistance decrease and not only to the number or strength of the existing bonds.

Fig. 2 shows the effect of cellulose-binding domains on the properties of pulp and paper. CBD1 and CBD2 identify two solutions obtained from different batches of Celluclast proteolytic digestion [15]. Although solutions 1 and 2 led to different results, the pulp treatment with the cellulosebinding domains has revealed to be quite interesting. When CBD1 was applied, it was possible to achieve the simultaneous increase of pulp drainage rate and paper resistance indexes (specially tensile and burst) as compared with the control. The peptide concentration seems to be critical, as the lower dosages (0.4-1.4 mg protein/g o.d. pulp) were quite favorable to the process (maximum increase in drainage of $14 \%$, together with an increase of $9 \%$ in burst and $7 \%$ in tensile), and the highest dosage $(2.8 \mathrm{mg}$ protein $/ \mathrm{g}$ o.d. pulp) was responsible for less favorable results (increase of $12 \%$ in drainage, followed by a $4 \%$ increase in burst and tensile resistance). It seems that the CBD binding to the fiber surface, by modifying the surface/interfacial properties of the fibers, affects the technical properties of the pulp and paper in a very positive way. Although it is still not possible to establish the kind and the importance of these changes to the modification of the properties of pulp and paper, it could be hypothesized that an excess of CBD reduces the mechanical peeling effect of fines from the surface of fibers and consequently worsens the final pulp characteristics. Cellulose degradation measurements revealed that no soluble sugars were detectable during the pulp treatment, which allows us to assure that the fiber modifications are not related to the enzymatic hydrolysis. Furthermore, the sheets obtained with this pulp did not show any change in the density or permeability parameters (data not shown) as previously observed during the enzymatic assays.

CBD2 preparation was able to produce a more significant ${ }^{\circ} \mathrm{SR}$ decrease (up to $30 \%$ ) but at the expense of some of the paper resistance. Only the tensile strength was slightly improved, when the lowest CBD dosage was applied. The treatment of the pulp with CBD2 produced a $0.2 \%-0.3 \%$ sugar solubilisation. Although these values are low, it seems obvious that there was some residual enzymatic activity in the CBD2 solution, which was probably responsible for the different results obtained. In this case, both $\mathrm{CBD}$ and enzyme may be acting on the fiber and affecting the pulp properties. The CBD concentration also happens to be critical as the pulp drainage rate and strength loss increases depended on it. As in the enzymatic assays, permeability and density parameters changed after treatment with Solution CBD2. The first increased, showing that at least some of the filler material was lost and the second decreased.

\subsection{Factors influencing enzymatic treatment of secondary fiber: enzyme dosage and reaction time}

As shown in the previous section, Celluclast $1.5 \mathrm{~L}$, Primalco $G$, Primalco H, Ecostone L and Viscozyme produced similar and very positive changes in fiber-water interactions. In order to optimize the effects of the enzymes in the technical paper properties, two of those enzymes (Celluclast $1.5 \mathrm{~L}$ and Primalco $G$ ) were tested under different experimental conditions, namely dosage and reaction time, such that the importance of these two parameters on the enzymatic treatment of secondary pulps could be better evaluated.

According to the cellulose degradation measurements obtained after the pulp treatment with Celluclast $1.5 \mathrm{~L}$, the amount of released sugars depended on both the applied enzyme concentration and reaction time. The 10-min reaction (0.1-0.2 FPU) presented the lower \% solubilisation $(0.2-0.3 \%)$, followed by the $30-$ min reaction (0.1-1.7 FPU) with $0.4-2.6 \%$ solubilisation and the 120 -min reaction $(0.2$ FPU) with $1.6 \%$. The effect of the same enzyme in the pulp and paper properties is shown in Fig. 3. The first main conclusion that can be drawn is that both the enzyme concentration and the reaction period considerably affected pulp and paper properties. The enzymatic modification of the pulp drainage and paper strength seems to be time dependent. Increasing the enzyme concentration produced the same kind of modification, but also turned visible that the tendency was limited to a certain value. According to the "peeling effect" theory presented by Pommier et al. (1989), drainage increase is limited to the point when enzyme action turns to be so intense that fiber length and fines content are affected. At this moment, drainage improvement will stop and paper mechanical properties start to decrease dramatically. 


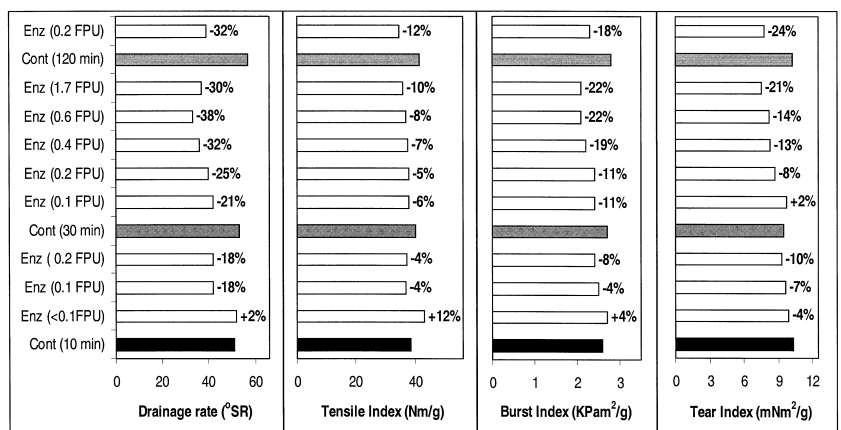

Fig. 3. Effect of Celluclast $1.5 \mathrm{~L}$ on the pulp and paper properties (old paperboard containers).

The "peeling effect" theory can only be applied to the higher enzyme dosages $(>0.4$ FPU) or longer reaction periods $(120 \mathrm{~min})$ situations, where enzymatic action was shown to be important. When the \% solubilisation of the cellulose is lower, the pulp and paper properties changes require another explanation.

Fig. 4 shows the effect of Primalco $G$ concentration on the old paperboard containers pulp and paper properties. According to the results, the enzymatic activity of this enzyme is also related to the physical properties of pulp and paper (cellulose degradation values varied in the range $1.1 \%$ $1.7 \%$ ). It was possible to decrease the enzyme dosage so that paper strength properties were less affected. Nevertheless, the worsening of the pulp drainage could not be avoided.

\subsection{Enzyme action on different fiber-length fractions}

Previous reports suggested a preferential degradation of fines and shorter fiber from pulps by the enzymes $[1,11,13$, 14], as a consequence of the higher surface area of these particles. The interest of the present study was to evaluate the response of two fiber-length fractions to the enzymatic treatment and to compare these results with the ones obtained with the enzymatic treatment of the non-fractionated pulp. The reactions took place in the presence of different dosages of Celluclast 1.5L (0.4, 1.0 and 2.0 FPU per $\mathrm{g}$ of dry pulp).

Table 2 shows the $\%$ of solubilised cellulose after the enzymatic hydrolysis. The amount of sugars released tends to be higher for the smaller fiber fraction (especially when 2.0 FPU was used), which probably indicates a higher

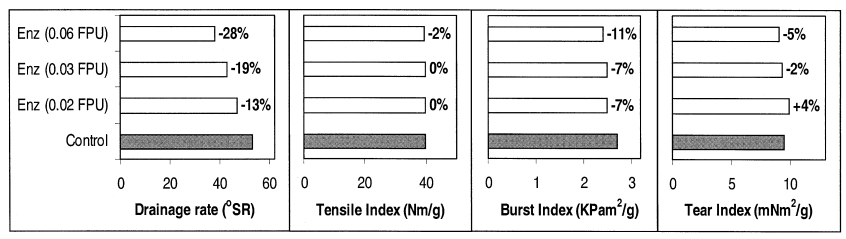

Fig. 4. Effect of Primalco $G$ on the pulp and paper properties (old paperboard containers).
Table 2

Quantification of cellulose degradation (\% solubilisation)

\begin{tabular}{llll}
\hline Sample $\backslash$ Celluclast 1.5 L dosage & $0.4 \mathrm{FPU}$ & $1.0 \mathrm{FPU}$ & $2.0 \mathrm{FPU}$ \\
\hline 200-50 mesh & 0.9 & 1.8 & 3.7 \\
$>30$ mesh & 0.7 & 1.7 & 3.2 \\
Non-fractionated & 1.0 & 1.9 & 4.0 \\
\hline
\end{tabular}

affinity of the enzymes for the shorter fractions, as previously suggested.

Physical testing showed that the fractionated samples and the original pulp responded similarly to the enzyme treatment (Fig. 5). All fiber fractions showed an increase in drainage at the expense of some of the strength. The single significant exception was the tensile strength, which declined after the enzymatic treatment of the mixed fibers pulp but increased in the fractionated samples, especially in the shorter fiber fraction. This has been reported as the result of fiber flattening, which enlarges the available surface for bonding and consequently increases the number of effective fiber-to-fiber bonds $[12,13,21]$. The results highlight the importance of the smaller fiber fractions in forming the tighter fibrous network, responsible for a well-bonded, strong paper product.

Increase in enzyme dosage accentuated the described effects. 1.0 FPU was the limiting enzyme concentration as beyond this value both drainage and strength decreased. The tensile improvement observed in the fractionated pulps was also dependent on the enzyme dosage, as the detected benefit tends to diminish with increasing enzyme dosage.

\section{Conclusions}

The present work shows the effect of several glycanases on a secondary fiber pulp. Most enzymes improve drainability, at the same time leading to substantial decrease of strength properties. To minimize these losses, a large number of factors have to be accounted for, the pulp composition and fiber structure probably being very important, as they greatly affect the enzymatic performance. However, as evidenced by the fact that cellulose-binding domains alone

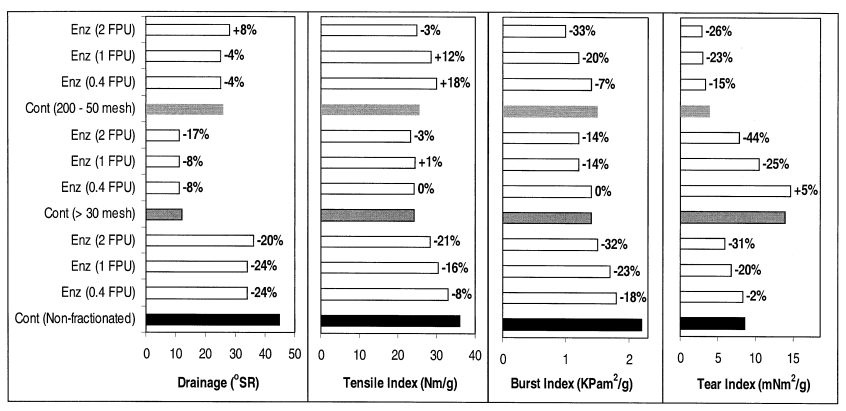

Fig. 5. Effect of Celluclast $1.5 \mathrm{~L}$ on the pulp and paper properties (fractionated samples). 
may modify the fibers properties, it seems likely that protein adsorption may modify the interfacial properties in such a way that pulp drainability and paper strength become modified. Irrespective of this effect, the hydrolytic activity may strikingly affect the fibers, as demonstrated by the fact that different enzymes lead to different effects. Cellulases have quite detrimental effects on the paper strength properties (Ecostone, Pergalase, P.ocitanis L/S). Xylanases, while improving drainability, cause no damage to the strength properties (Xylanase C482). Each pulp represents a new challenge, requiring a careful study defining the more effective enzyme and process. The reported experiments also seem to indicate that no upgrade is possible without establishing a drainage/strength compromise.

Low enzyme dosages and short reaction periods seem to be advisable, with the advantage that sugar solubilisation is lower. Actually, by treating the old paperboard containers pulp with Celluclast $1.5 \mathrm{~L}$ and Primalco $G$ it was possible to increase drainage with limited strength lost. Whatever the mechanism of fiber modification by the enzymes, it is very interesting to remark that little time is required to introduce such modifications. It has also been shown that fiber response to enzymes depends on its length. Generally, the shorter fibers are more susceptible to the enzymatic attack than the longer, as they present a wider specific surface area to the enzymes.

The use of cellulose-binding domains may be a very attractive method of treating secondary paper pulps. In this work, we report for the first time the possibility of achieving the simultaneous increase of the resistance and drainage rate. The action of the cellulose-binding domains on the fibers is still unknown but it seems to be due to their adsorption to the fiber surface, which alters the fiber surface characteristics.

\section{Acknowledgment}

The authors gratefully thank Portucel Viana the use of laboratory facilities for the pulp and paper characterization.

\section{References}

[1] Pommier JC, Fuentes JL, Goma G. Using enzymes to improve the process and the product quality in the recycled paper industry-Part 1 : the basic laboratory work. Tappi J 1989;72(6):187-91.
[2] Nazhad MM, Paszner L. Fundamentals of strength loss in recycled paper. Tappi J 1994;77(9):171-9.

[3] Marton R, Brown A, Granzow S, Koeppicus R, Tomlinson S. Recycling and fiber structure. Progress in Paper Recycling 1993:58-70.

[4] Bhat GR, Heitmann JA, Joyce TW. Novel techniques for enhancing the strength of secondary fiber. Tappi J 1991;74(9)151-7.

[5] Allen LH, Yaraskavitch IM. Effects of retention and drainage aids on paper machine drainage: a review. Tappi J 1991;74(7)79-84.

[6] Stork G, Puls J. Change in properties of different recycled pulps by endoglucanase treatment. $6^{\text {th }}$ Int Conf Biotechnol Pulp and Paper Ind 1994:145-50.

[7] Stork G, Pereira H, Wood TM, Dusterhoft E, Toft A, Puls J. Upgrading recycled pulps using enzymatic treatment. Tappi J 1995;78(2): 79-88.

[8] Pere J, Siika-aho M, Buchert J, Viikari L. Effects of purified Trichoderma reesei cellulases on the fiber properties of Kraft pulp. Tappi J 1995;78(6):71-8.

[9] Ryan SE, Jong E, Gubitz GM, Tuohy M, Saddler JN. The potential of hydrolytic enzymes to modify Douglas fir derived bleached mechanical pulps. Carbohydrases from Trichoderma reesei and Other Microorganisms, 214-226.

[10] Ryan SE, De Jong E, Gubitz GM, Tuohy M, Saddler JN. Enzymatic modification of pre-treated Douglas-fir refiner pulp. $7^{\text {th }}$ Int Conf of Biotechnol Pulp and Paper Ind 1998;C:C147-C150.

[11] Jackson LS, Heitmann JA, Joyce TW. Enzymatic modifications of secondary fiber. Tappi J 1993;76(3):147-54.

[12] Mansfield SD, Swanson DJ, Roberts N, Olson JA, Saddler JN. Enhancing Douglas-fir pulp properties with a combination of enzyme treatments, and fiber fractionation. Tappi J 1999;82(5):152-8.

[13] Mansfield SD, Wong KKY, Jong E, Saddler JN. Modification of Douglas-fir mechanical and Kraft pulps by enzymatic treatment. Tappi J 1996;79(8):125-32.

[14] Mooney CA, Mansfield SD, Beatson RP, Saddler JN. The effect of fiber characteristics on accessibility and hydrolysis of softwood substrates. $7^{\text {th }}$ Int Conf Biotechnol Pulp and Paper Ind 1998;C:C99C102.

[15] Suurnakki, Heijnesson A, Buchert J, Westermark U, Viikari L. Effect of pulp surfaces on enzyme-aided bleaching of Kraft pulps. JPPS 1996;22(3):J91-J96.

[16] Kaya F, Heitmann JA Jr, Joyce TW. Cellulase binding to cellulose fibbers in high shear fields. J Biotechnol 1994;36:1-10.

[17] Bradford MM. A rapid, and sensitive method for the quantification of microgram quantities of protein utilising the principle of protein-dye binding. Anal Biochem 1976;72:248-54.

[18] Bernfeld P. In: Collowick SP, Kaplan ND, editors. Methods in Enzymology. NY: Academic Press, 1995. p. 149-52.

[19] Lemos MA, Teixeira JA, Mota M, Gama FM. A simple method to separate cellulose-binding domains of fungal cellulases after digestion by a protease. Biotechnol Lett 2000;22:703-7.

[20] Gubitz GM., Lischnig T, Stebbing D, Saddler JN. Enzymatic removal of hemicellulose from dissolving pulps. Biotechnol Lett 1997;19(5): 491-5.

[21] Mansfield SD, Dickson AR, Saddler JN. Improving paper properties by selective enzymatic treatment of coarse pulp fibers. $7^{\text {th }}$ Int Conf of Biotechnol Pulp and Paper Ind 1998;A:A189-A193. 